Article

\title{
Determining Equipment Capacity of Electric Vehicle Charging Station Operator for Profit Maximization
}

\author{
Se Hoon Baik ${ }^{1}$, Young Gyu Jin ${ }^{2, *}$ and Yong Tae Yoon ${ }^{1}$ \\ 1 Department of Electrical and Computer Engineering, Seoul National University, 1 Gwanak-ro, Gwanak-gu, \\ Seoul 08826, Korea; 201622241@snu.ac.kr (S.H.B.); ytyoon@snu.ac.kr (Y.T.Y.) \\ 2 Department of Electrical Engineering, Jeju National University, 102 Jejudaehak-ro, Jeju-si 63243, Korea \\ * Correspondence: ygjin93@jejunu.ac.kr; Tel.: +82-64-754-3677
}

Received: 30 July 2018; Accepted: 28 August 2018; Published: 1 September 2018

\begin{abstract}
Related to global efforts to reduce greenhouse gases, numerous electric vehicles (EVs) are expected to be integrated to the power grid. However, the introduction of EVs, particularly in Korea, is still marginal due to the lack of EV charging infrastructure, even though various supportive policies exist. To address this shortage of EV charging stations, the EV charging business needs to be profitable. As with any business, the profitability of the EV charging business is significantly affected by the initial capital investment related to EV chargers and auxiliary equipment such as power conditioning system (PCS), battery energy storage system (BESS), and on-site photovoltaic $(\mathrm{PV})$ generation system. Thus, we propose a formulation to determine the number of EV chargers and the capacity of auxiliary equipment with the objective of a charging station operator (CSO) maximizing profit under regulatory, economic, and physical constraints. The effectiveness of the proposed method is verified with simulations considering various EV charging patterns. The study results will help improve the EV charging infrastructure by encouraging individuals and companies to participate in EV charging business.
\end{abstract}

Keywords: electric vehicle; charging station; charging station operator; profit maximization

\section{Introduction}

Recently, electric vehicles (EVs) have been attracting great interest as a promising solution to climate change because they reduce greenhouse gas emissions [1-3]. Indeed, the number of EVs is forecast to be over 100 million worldwide by 2030 [4]. To expand the number of EVs, various policies have been implemented globally. For example, incentives to purchase and use EVs include rebates at registration, tax exemptions, and waivers on access restrictions [4]. Korea is not an exception to this trend. The Korean government and local authorities provide subsidies and tax cuts for EV purchases [5]. However, despite these supportive policies, the introduction of EV is still marginal, particularly in Korea [6]. One of the fundamental reasons for this weak introduction of EVs is the lack of charging infrastructure. Thus, the problem of insufficient charging stations needs to be addressed to expand the number of EVs in the near future.

Several studies have examined the purpose of improving EV charging infrastructure. Some researchers have studied methods to enable uninterrupted transportation operation with minimum negative environmental externalities by substituting EVs with internal combustion vehicles with EVs [7-9]. Dong et al. [7] examined the impact of the deployment level of charging infrastructure on reducing EV range anxiety. Kontou et al. [8] described the method of minimizing the cost of replacing gas-powered cars with battery electric ones, where the cost includes investment for the deployment of charging infrastructure. Luo et al. [9] described a method minimizing the annual social cost while considering the range anxiety of EV owners. Román et al. [10] described 
a general business scheme including commercial relationships between EV charging station and involved agents, while Madina et al. [11] proposed a method to assess EV charging infrastructure business model. Sweda and Klabjan [12] analyzed a decision support system for deploying new charging infrastructure. Liu [13] presented a grid impact assessment of charging infrastructure deployment in Beijing. Trivedi et al. and Liu et al. described optimal sizing and siting methods of EV charging station for power system operator to reduce network loss and improve voltage profile in distribution network $[14,15]$. Some researchers studied methods of minimizing integrated cost of EV charging station infrastructure [16-18]. In addition, Chandra Mouli et al. [19] presented EV charging station designed to maximize energy yield considering the operation of photovoltaic (PV) systems, where sensitivity analyses are used to decide a proper capacity of the battery energy storage system (BESS). Furthermore, Bai et al. [20] presented research on EV charging station design with sizing and topology selection of storage system to satisfy peak power demand.

Not only is the role of utilities for the whole power system significant, but the active participation of individuals and/or companies is also important to improve the infrastructure by increasing the number of EV charging stations. For instance, in the case of internal combustion vehicles, gas stations are highly accessible because of their high density, while EV drivers necessarily undergo inconvenience because of the small number of EV charging stations. The principal factor that encourages the participation of EV charging station operators (CSOs) EV charging business is profitability. As with any other business, the profitability of EV charging business is significantly affected by the initial capital investment related to EV chargers and the auxiliary equipment, such as the power conditioning system (PCS), BESS, and on-site PV system. In other words, it is important for a prospective CSO to determine the suitable number of EV chargers and capacity of auxiliary equipment.

Nevertheless, previous studies mainly deal with the deployment of EV charging stations from the perspective of utilities to reduce grid impacts or from the perspective of a certain region to minimize the integrated cost. Moreover, such studies that are not from the perspective of an individual CSO are limited to countries with a strong incentive to develop a CSO business or with a resourceful entity that can deploy EV charging infrastructure by itself. Although some studies $[10,19,20]$ have been conducted from the perspective of an individual CSO, the general business scheme, energy yield maximization method, or sizing and topology selection of the storage system that these studies provide are insufficient to encourage participation in EV charging business. This is because they do not address the subject of the optimal investment decision of an individual CSO that guarantees profitability of a CSO business.

To bridge this gap in the body of knowledge, in this study, we propose a novel methodological framework from the perspective of an individual CSO to determine optimally the number of EV chargers and capacity of auxiliary equipment with the objective of maximizing the profit of a CSO. In our formulation, the physical constraints are considered as well as the regulatory and economic ones. The effectiveness of the proposed method is then verified with the simulations that account for the specific conditions in Korea. Various charging patterns are considered in the simulations as well as the change of the charging pattern with respect to the return on investment.

The remainder of the paper is organized as follows. Section 2 describes the regulatory background about EV charging business in Korea. Section 3 presents the formulation for the optimal investment decision of a CSO. Section 4 describes the cases and Section 5 discusses the case study results by using the proposed method. Finally, Section 6 concludes.

\section{Regulatory Background}

To determine the optimal investment decision of a CSO, it is necessary to analyze the regulations of an individual country regarding the CSO business. In this section, as an example for the case study, we describe the associated regulations in Korea, such as hourly and seasonal charging fee for EVs, fee discount for energy storage system (ESS) installation and operation, and infrastructure linkage fee. 


\subsection{Charging Fee of EV}

An electricity customer may choose one of two ways to purchase its supply of electrical power: buy power from the utility, Korea Electric Power Corporation (KEPCO), and participate in the energy market directly if the customer satisfies the criterion that its load capacity at a single location is at least $30,000 \mathrm{kVA}[21,22]$. Considering that charging power of an EV is $3-22 \mathrm{~kW}$, the load capacity of a CSO is unlikely to meet the above condition for participating in the energy market. Thus, it is assumed in this study that the CSO is supplied with electricity by the utility based on its own charging scheme. The EV charging fee in Korea varies with voltage level, hour, and season [23]. Tables 1 and 2 list the detailed structure and specific values of the EV charging fee in Korea, respectively.

Table 1. EV charging structure in Korea.

\begin{tabular}{cccc}
\hline Category & $\begin{array}{c}\text { Summer } \\
\text { (1 June-31 August) }\end{array}$ & $\begin{array}{c}\text { Spring/Fall (1 March-31 May, } \\
\text { 1 September-31 October) }\end{array}$ & $\begin{array}{c}\text { Winter } \\
\text { (1 November-28 February) }\end{array}$ \\
\hline Light load hours & $23: 00-09: 00$ & $23: 00-09: 00$ & 23:00-09:00 \\
\hline \multirow{2}{*}{ Heavy load hours } & $09: 00-10: 00$ & $09: 00-10: 00$ & $09: 00-10: 00$ \\
& $12: 00-13: 00$ & $12: 00-13: 00$ & $12: 00-17: 00$ \\
& $17: 00-23: 00$ & $17: 00-23: 00$ & $20: 00-22: 00$ \\
\hline \multirow{2}{*}{ Peak load hours } & $10: 00-12: 00$ & $10: 00-12: 00$ & $10: 00-12: 00$ \\
& $13: 00-17: 00$ & $13: 00-17: 00$ & $22: 00-23: 00$ \\
\hline
\end{tabular}

Table 2. Specific values for EV charging fee in Korea.

\begin{tabular}{|c|c|c|c|c|c|}
\hline & & egory & Summer & Spring/Fall & Winter \\
\hline \multirow{4}{*}{$\begin{array}{l}\text { Low voltage } \\
\text { customer }\end{array}$} & \multirow{3}{*}{$\begin{array}{l}\text { Energy fee } \\
\text { (KRW/kWh) }\end{array}$} & Light load hours & 57.6 & 58.7 & 80.7 \\
\hline & & Heavy load hours & 145.3 & 70.5 & 128.2 \\
\hline & & Peak load hours & 232.5 & 75.4 & 190.8 \\
\hline & \multicolumn{2}{|c|}{ Capacity charge (KRW/kW) } & & 2390 & \\
\hline \multirow{4}{*}{$\begin{array}{l}\text { High voltage } \\
\text { customer }\end{array}$} & \multirow{3}{*}{$\begin{array}{l}\text { Energy fee } \\
\text { (KRW/kWh) }\end{array}$} & Light load hours & 52.5 & 53.5 & 69.9 \\
\hline & & Heavy load hours & 110.7 & 64.3 & 101 \\
\hline & & Peak load hours & 163.7 & 68.2 & 138.8 \\
\hline & \multicolumn{2}{|c|}{ Capacity charge (KRW/kW) } & & 2580 & \\
\hline
\end{tabular}

\subsection{Charge Discount}

According to a recent policy that aimed to expand the use of renewable energy and ESS integration to the power grid, a CSO can receive a charge discount for the installation and operation of a PV system and an ESS in Korea. The discount is classified into four types: the energy fee discount for the PV system, capacity charge discount for the ESS, energy fee discount for the ESS, and additional energy fee discount for installing both a PV system and an ESS [23,24].

The energy fee discount for PV system is the product of $1 / 2$, self-consumption of PV generation, and the average energy price during peak and heavy load hours of the previous year. The capacity charge discount for ESS is the product of $1 / 3$, weight factor A, the unit capacity charge for the customer, and the sum of average difference between discharged and charged energy during peak load hours on weekdays in a month. The upper limit of the capacity charge discount for ESS is the higher value between the monthly capacity charge and the unit price of capacity charge times the capacity of BESS. The energy fee discount for ESS is the product of 1/2, weight factor A, and a CSO's energy fee payment during the light load hours. The additional energy fee discount is applied only for customers that install and operate both PV system and ESS whose value is the product of $1 / 2$, weight factor B, energy amount of self-consumption of PV generation, and average unit price of energy fee during peak and heavy load hours of the previous year. There are some exceptions for the discount, such as the use 
of the ESS for stabilizing PV output or frequency regulation. However, EV charging is not included in the exception cases, and thus a CSO can obtain the discount. All discounts except the energy fee discount for the PV system are applied by weight factors determined by the ratio of capacity of BESS and contract demand, as shown in Table $3[23,24]$.

Table 3. Weight factors applied to the charge discount in Korea.

\begin{tabular}{ccc}
\hline $\begin{array}{c}\text { Ratio of the Capacity of the } \\
\text { BESS and Contract Demand }\end{array}$ & Weight Factor A & Weight Factor B \\
\hline Over 10\% & 1.2 & 0.5 \\
Over 5\% and less than $10 \%$ & 1 & 0.2 \\
Less than $5 \%$ & 0.8 & 0 \\
\hline
\end{tabular}

\subsection{Infrastructure Linkage Fee}

The infrastructure linkage fee in Korea is defined as the fee paid by a customer for necessary equipment reinforcement or construction below the connection point when the customer is newly connected to the grid or when the customer requests an increase in capacity [25]. Accordingly, a new CSO needs to pay for the infrastructure if necessary. The infrastructure linkage fee is classified into two types: basic fee and distance fee. Tables 4 and 5 list the specific values of these fees in Korea [25]. The distance fee is not considered in the case study because the proposed optimization method does not determine the location of the CSO; hence, the distance between the connection point and CSO cannot be calculated.

Table 4. Basic infrastructure linkage fee.

\begin{tabular}{cccc}
\hline \multicolumn{2}{c}{ Category } & Overhead & Underground \\
\hline Low voltage linkage fee (KRW) & $\begin{array}{c}\text { Per contract, up to 5 kW } \\
\text { contract demand }\end{array}$ & 220,000 & 421,000 \\
\cline { 2 - 4 } & $\begin{array}{c}\text { Per kW, over 5 kW contract } \\
\text { demand }\end{array}$ & 86,000 & 98,000 \\
\hline $\begin{array}{c}\text { High or extra high voltage } \\
\text { linkage fee (KRW) }\end{array}$ & Per kW of contract demand & 17,000 & 35,000 \\
\hline
\end{tabular}

Table 5. Distance infrastructure linkage fee.

\begin{tabular}{|c|c|c|c|c|c|}
\hline \multirow{2}{*}{\multicolumn{3}{|c|}{ Category }} & \multicolumn{2}{|c|}{ Overhead } & \multirow{3}{*}{$\begin{array}{c}\text { Underground } \\
60,000 \\
\end{array}$} \\
\hline & & & Single Phase & Three Phase & \\
\hline \multirow{2}{*}{$\begin{array}{c}\text { Construction linkage } \\
\text { fee }(K R W)\end{array}$} & \multirow{2}{*}{$\begin{array}{c}\text { Per } \mathrm{m} \text {, over basic } \\
\text { distance }\end{array}$} & Low voltage & 39,000 & 43,000 & \\
\hline & & $\begin{array}{l}\text { High or extra } \\
\text { high voltage }\end{array}$ & \multicolumn{2}{|c|}{43,000} & 110,000 \\
\hline \multirow{2}{*}{$\begin{array}{c}\text { Reinforcement } \\
\text { linkage fee (KRW) }\end{array}$} & \multirow{2}{*}{$\begin{array}{c}\text { Per } \mathrm{m} \text {, over basic } \\
\text { distance }\end{array}$} & Low voltage & \multicolumn{2}{|c|}{5000} & - \\
\hline & & $\begin{array}{l}\text { High or extra } \\
\text { high voltage }\end{array}$ & \multicolumn{2}{|c|}{10,000} & - \\
\hline
\end{tabular}

\section{Optimization Formulation}

The purpose of the formulation is to maximize the net present value (NPV) of a CSO under regulatory, economic, and physical constraints. Thus, the objective function of the optimization problem is expressed as

$$
\max N P V=\max \left\lfloor\left(\sum_{d=1}^{365}(R E V(d)-E X(d))-12 C_{e v} u_{c}+C D\right) \cdot \frac{1-\left(\frac{1}{1+r_{\text {disc }}}\right)^{N-1}}{1-\frac{1}{1+r_{\text {disc }}}}-E X_{0}\right\rfloor
$$


Equations (2) and (3) present the revenue and operating expenditure for each day, respectively. Equation (4) describes the relationship between the buying and selling prices of electricity. Daily uniform selling price is chosen to prevent charging demand from being affected by hourly changing selling prices, such that EV charging is focused at certain low-priced hours:

$$
\begin{aligned}
R E V(d) & =\sum_{h=1}^{24} \rho_{u}(d) P_{e v}(h, d) C_{e v} \\
E X(d) & =\sum_{h=1}^{24} \rho_{b}(h) P_{\text {grid }}(h, d) \\
\rho_{u}(d) & =\frac{\sum_{h=1}^{24}(1+M) \rho_{b}(h)}{24}
\end{aligned}
$$

The initial capital expenditure of the CSO is expressed as

$$
E X_{0}=C_{p c s} u_{p c s}+C_{b} u_{b}+C_{p v} u_{p v}+C_{e v}\left(u_{e v}+R_{c} u_{i}\right)
$$

The value in Equation (6) should be less than the allowed budget, which is expressed as

$$
E X_{0} \leq E X_{0}^{\max }
$$

The power balance condition that the net power flow between the CSO and grid should be equal to zero is formulated as

$$
P_{\text {grid }}(h, d)-P_{c h}(h, d)+P_{d c h}(h, d)+P_{p v}(h, d) C_{p v}-P_{e v}(h, d) C_{e v}=0
$$

where the parameters of $P_{p v}(h, d)$ and $P_{e v}(h, d)$ are given as the ratio because the values of the decision variables, $C_{p v}$ and $C_{e v}$, are not yet determined. Accordingly, it is assumed that PV generation and EV charging demand are each proportional to the capacity of the PV and EV chargers. The constraint that the power import from the grid should be limited is given as

$$
P_{\text {grid }}(h, d)<R_{c} C_{e v}
$$

Equations (9)-(11) describe the constraints for the hourly remaining energy of BESS:

$$
\begin{gathered}
E_{b}(h, d),(h=1)=S O C_{0} C_{b}+P_{c h}(h, d) \eta_{c h}-\frac{P_{d c h}(h, d)}{\eta_{d c h}} \\
E_{b}(h, d),(h>1)=E_{b}(h-1, d)+P_{c h}(h, d) \eta_{c h}-\frac{P_{d c h}(h, d)}{\eta_{d c h}} \\
S O C_{\text {min }} C_{b} \leq E_{b}(h, d) \leq S O C_{\text {max }} C_{b}
\end{gathered}
$$

Equations (12)-(15) show the constraints related to the hourly charging and discharging power of PCS. Equations (14) and (15) formulate the condition that charging and discharging operations are not performed simultaneously using the auxiliary variables of $y(h, d)$ and bigN [26]:

$$
\begin{gathered}
P_{c h}(h, d) \leq C_{p c s} \\
P_{d c h}(h, d) \leq C_{p c s} \\
P_{c h}(h, d) \leq y(h, d) b i g N \\
P_{d c h}(h, d) \leq(1-y(h, d)) b i g N
\end{gathered}
$$


Equation (16) describes the condition that the capacity of EV chargers can only be equal to the multiple of the capacity of a single EV charger:

$$
C_{e v}=C_{s e v} N_{e v}
$$

Equations (17) and (18) present the area-related constraints considering the following assumptions: an agency owns the land for the CSO business; only the remaining part of the area is allowed for the installation of EV chargers because some of the areas of a EV charging station should be used for vehicle movement; all the on-site PV generation systems are installed on the rooftop to make better use of the limited space; and the area required for the ESS is ignored because it is relatively smaller than the area required for the other equipment:

$$
\begin{gathered}
R_{a} A_{\max } \geq \frac{A_{e v}}{C_{s e v}} C_{e v} \\
A_{\max } \geq A_{p v} C_{p v}
\end{gathered}
$$

\section{Case Descriptions}

The method presented in this study for the profit maximization of a CSO is verified by Korean cases. A CSO is highly likely to be a high-voltage customer of KEPCO because it needs to service multiple EVs. The EV charging fee for high-voltage customers of KEPCO is lower than that for low-voltage customers, as shown in Table 2. Additionally, the construction of overhead cables is physically impossible in numerous urban areas. Thus, it is assumed that the CSO is a high-voltage customer of KEPCO that receives electricity through underground cables, from a probabilistic point of view and to ensure competitive price.

\subsection{Simulation Setup}

The period of business $(N)$ and annual discount rate $\left(r_{\text {disc }}\right)$ are set to 20 years and $5 \%$, respectively. The capacity of a single EV charger $\left(C_{s e v}\right)$ is $7.7 \mathrm{~kW}$, and its required area $\left(A_{e v}\right)$ is set to $12.5 \mathrm{~m}^{2}$ [27]. The required area for a $1 \mathrm{~kW}$ rooftop PV system $\left(A_{p v}\right)$ is assumed $13 \mathrm{~m}^{2}$. The lower limit $\left(S O C_{m i n}\right)$, upper limit $\left(S O C_{\max }\right)$, and the initial value $\left(S O C_{0}\right)$ of state of charge $(\mathrm{SOC})$ are set to $0.1,1$, and 0.5 , respectively. The charging $\left(\eta_{c h}\right)$ and discharging efficiency $\left(\eta_{d c h}\right)$ of the PCS are 0.95 . The ratio of the area allowed for the EV chargers to the total area of EV charging station $\left(R_{a}\right)$ is 0.5 , and the ratio of the capacity of grid connection equipment to that of EV chargers $\left(R_{c}\right)$ is 1.5. The auxiliary big number $(b i g N)$ is set to 3000. Charge discount described in Section 2.2 is applied to charge discount for installation and operation of the PV system and ESS (CD).

The proposed method is implemented in GAMS environment on an Intel CPU i5-7500 3.4 GHz PC with 8 GB RAM, using mixed-integer linear programming solver.

\subsection{Unit Price of Equipment}

Since the unit price of equipment is a principal factor for determining its capacity, it is necessary to reflect market conditions in case studies to yield a reasonable solution. Table 6 lists the unit prices of the necessary equipment of a CSO considering the recent market conditions [28-31].

Table 6. Unit prices of equipment.

\begin{tabular}{cc}
\hline Equipment & Unit Price \\
\hline PCS & $160,000(\mathrm{KRW} / \mathrm{kW})$ \\
BESS & $400,000(\mathrm{KRW} / \mathrm{kWh})$ \\
PV & $1,500,000(\mathrm{KRW} / \mathrm{kW})$ \\
EV charger & $450,000(\mathrm{KRW} / \mathrm{kW})$ \\
\hline
\end{tabular}




\subsection{Patterns of EV Charging Demand}

The annual EV charging pattern is generated by adding 8760 random numbers to a reference pattern. For the reference EV charging pattern, three cases are considered to investigate the change in a CSO's investment decision with respect to the property of EV customers. The patterns are denoted as Case A, Case B, and Case C, which represent the charging patterns for commercial buildings, a commercial area with overtime work, and a residential area, respectively. Their specific values are obtained from an EV charging-related company in Korea.

\subsubsection{Case A}

This case represents the EV charging pattern for general commercial buildings. Figure 1 illustrates the information on the annual EV charging pattern based on this reference pattern, showing that EV charging does not occur in non-working hours (0-4 h and 20-24 h).

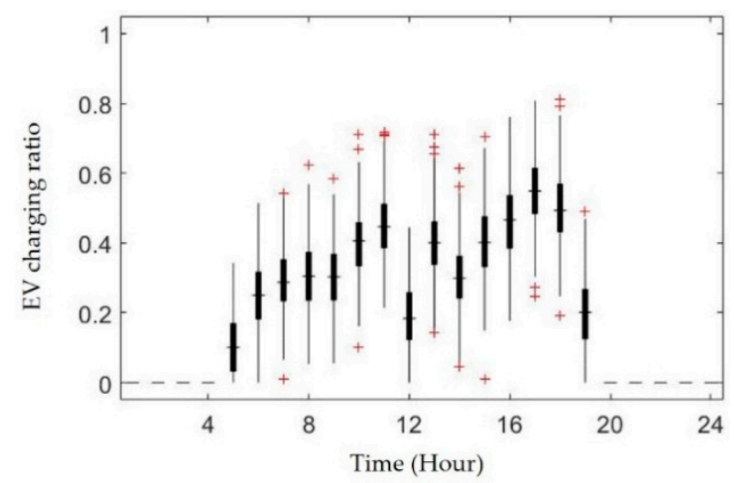

Figure 1. Statistical information on annual EV charging pattern for Case A.

\subsubsection{Case B}

This case represents the EV charging pattern for a commercial area with overtime work. Figure 2 illustrates the information on this annual EV charging pattern, showing that EV charging occurs after closing hours and not during nighttime $(2-4 \mathrm{~h})$.

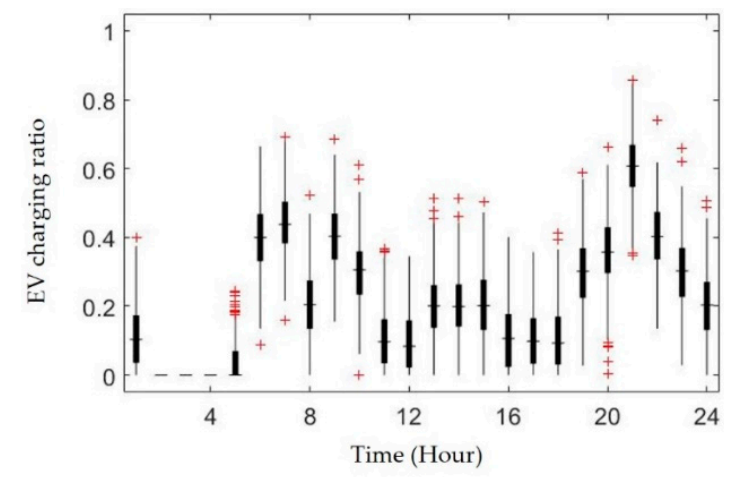

Figure 2. Statistical information on annual EV charging pattern of Case B.

\subsubsection{Case C}

This case represents the EV charging pattern for a residential area. Figure 3 shows the information on this annual EV charging pattern. It is assumed that the EV charging demand of residential customers is relatively uniform throughout the day. 




Figure 3. Statistical information on annual EV charging pattern of Case C.

\subsection{PV Generation}

PV generation data during a year are calculated as a function of weather conditions, such as irradiance and temperature [32], using the weather data from 2016 on Manhattan, New York in the United States, a city in the mid-latitude region with four seasons [33]. Figure 4 shows the statistical information on annual PV generation.



Figure 4. Statistical information on annual PV generation.

\subsection{Relationship between Selling Price and EV Charging Demand}

There is a relationship between EV charging demand and the selling price of a CSO because EV customers may move to other charging stations that offer a cheaper price. Thus, charging demand is likely to decrease if the selling price of a CSO increases. Further, the selling price depends on the desired profit margin of a CSO. Consequently, the following relationship between the EV charging demand and the desired profit is assumed, where EV charging demand decreases from $100 \%$ to $55 \%$ if the selling price doubles:

$$
\Delta P_{e v}(h, d)=\left(-0.5 M^{2}-0.05 M\right) P_{e v}(h, d) .
$$

\subsection{Conditions of Budget, Area, and Desired Profit Margin}

The simulations are conducted for each EV charging pattern case under different budget, area, and desired profit margin conditions. As for the budget and area, two cases of 50,000,000 KRW in $200 \mathrm{~m}^{2}$ (a relatively small charging station) and 200,000,000 KRW in $1500 \mathrm{~m}^{2}$ (a relatively large charging station) are considered. For the desired profit margin, nine cases from $10 \%$ to $90 \%$ are simulated. Note that the NPV of a CSO does not continue to increase with the rise in the desired profit margin because of the relationship in Equation (19). 


\section{Results and Discussion}

\subsection{Simulation Results}

Tables 7-9 present the simulation results of the optimal capacity of equipment and the corresponding NPV for the three cases with base unit prices of equipment.

Table 7. Simulation results for Case A with base unit prices of equipment.

\begin{tabular}{|c|c|c|c|c|c|c|c|}
\hline $\begin{array}{c}\text { Budget } \\
\text { (1000 KRW) }\end{array}$ & Area $\left(\mathbf{m}^{2}\right)$ & $\begin{array}{c}\text { Desired Profit } \\
\text { Margin Added to } \\
\text { the Price ( } \%)\end{array}$ & $\begin{array}{c}\text { PCS } \\
\text { Capacity } \\
(\mathbf{k W})\end{array}$ & $\begin{array}{c}\text { BESS } \\
\text { Capacity } \\
(\mathbf{k W h})\end{array}$ & $\begin{array}{c}\text { PV } \\
\text { Capacity } \\
(\mathbf{k W})\end{array}$ & $\begin{array}{l}\text { EV Charger } \\
\text { Capacity } \\
(\mathbf{k W})\end{array}$ & $\begin{array}{l}\text { NPV (1000 } \\
\text { KRW) }\end{array}$ \\
\hline \multirow{7}{*}{50,000} & \multirow{7}{*}{200} & 20 & 12.56 & 28.4 & 14.1 & 30.8 & 20,718 \\
\hline & & 30 & 12.57 & 28.9 & 13.96 & 30.8 & 25,331 \\
\hline & & 40 & 11.6 & 20.72 & 13.67 & 38.5 & 29,199 \\
\hline & & 60 & 11.76 & 22.97 & 13.05 & 38.5 & 36,120 \\
\hline & & 70 & 10.34 & 16.66 & 12.3 & 46.2 & 36,726 \\
\hline & & 80 & 10.2 & 18.47 & 11.84 & 46.2 & 36,684 \\
\hline & & 90 & 10.1 & 20.74 & 11.24 & 46.2 & 33,321 \\
\hline \multirow{5}{*}{200,000} & \multirow{5}{*}{1500} & 10 & 48.7 & 122.04 & 56.9 & 115.5 & 63,010 \\
\hline & & 60 & 44.1 & 83.96 & 52.06 & 161.7 & 144,353 \\
\hline & & 70 & 43 & 82.03 & 50.12 & 169.4 & 148,923 \\
\hline & & 80 & 42.73 & 81.45 & 47.72 & 177.1 & 146,268 \\
\hline & & 90 & 41.19 & 75.22 & 44.39 & 192.5 & 132,576 \\
\hline
\end{tabular}

Table 8. Simulation results for Case B with base prices of equipment.

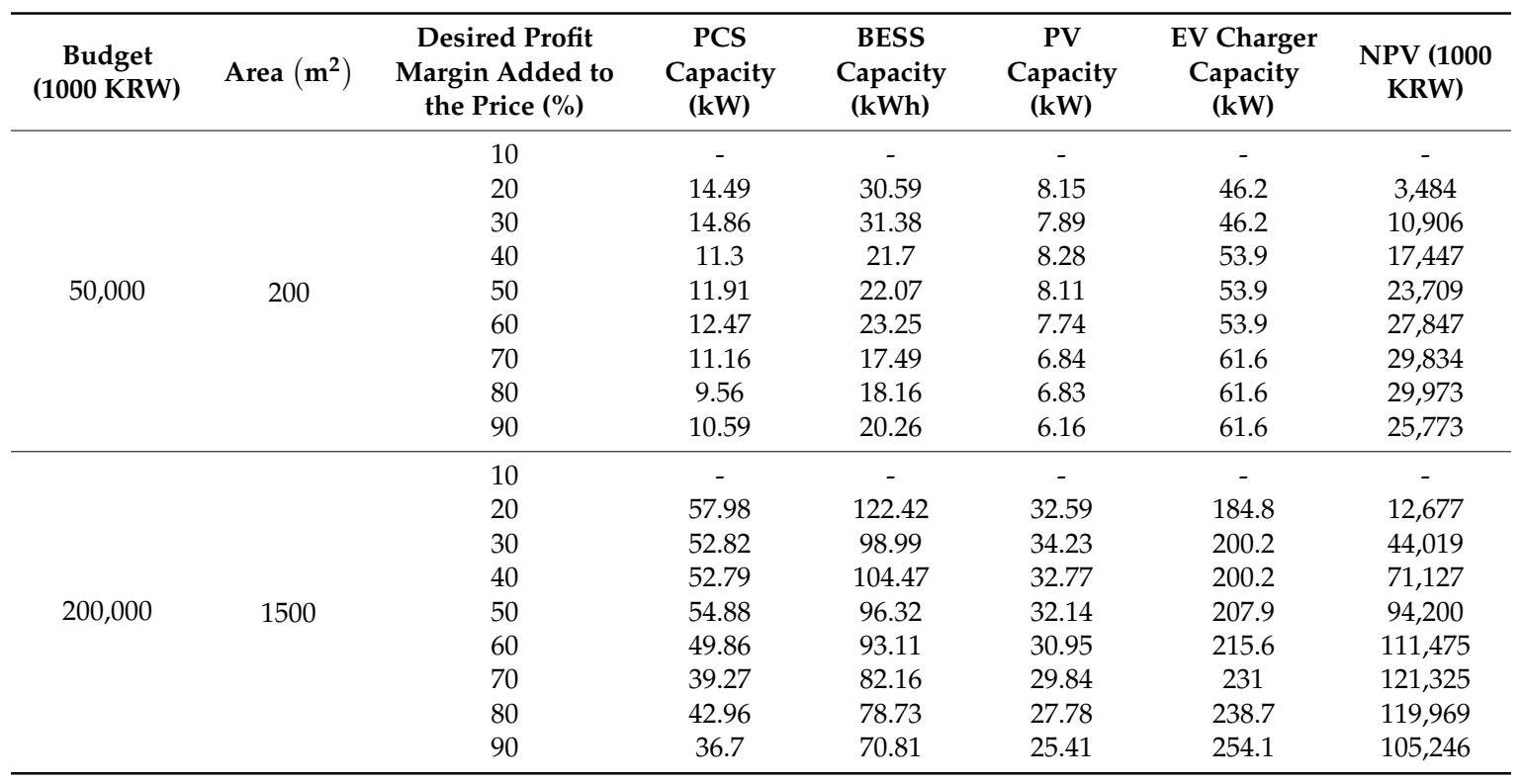


Table 9. Simulation results for Case $C$ with base prices of equipment.

\begin{tabular}{|c|c|c|c|c|c|c|c|}
\hline $\begin{array}{c}\text { Budget } \\
\text { (1000 KRW) }\end{array}$ & Area $\left(\mathbf{m}^{2}\right)$ & $\begin{array}{l}\text { Desired Profit } \\
\text { Margin Added to } \\
\text { the Price }(\%)\end{array}$ & $\begin{array}{c}\text { PCS } \\
\text { Capacity } \\
(\mathrm{kW})\end{array}$ & $\begin{array}{c}\text { BESS } \\
\text { Capacity } \\
(\mathbf{k W h})\end{array}$ & $\begin{array}{c}\text { PV } \\
\text { Capacity } \\
(\mathbf{k W})\end{array}$ & $\begin{array}{c}\text { EV Charger } \\
\text { Capacity } \\
(\mathbf{k W})\end{array}$ & $\begin{array}{l}\text { NPV (1000 } \\
\text { KRW) }\end{array}$ \\
\hline \multirow{9}{*}{50,000} & \multirow{9}{*}{200} & 10 & 14.54 & 29.78 & 10.94 & 38.5 & 7149 \\
\hline & & 20 & 14.89 & 30.42 & 10.73 & 38.5 & 13,680 \\
\hline & & 30 & 14.96 & 29.06 & 10.4 & 38.5 & 18,907 \\
\hline & & 40 & 12.08 & 24.15 & 10.12 & 46.2 & 25,137 \\
\hline & & 50 & 12.13 & 24.68 & 9.97 & 46.2 & 30,023 \\
\hline & & 60 & 12.25 & 25.3 & 9.8 & 46.2 & 33,109 \\
\hline & & 70 & 10.72 & 20.17 & 8.75 & 53.9 & 35,123 \\
\hline & & 80 & 10.23 & 20.94 & 8.6 & 53.9 & 34,206 \\
\hline & & 90 & 9.94 & 22.13 & 8.31 & 53.9 & 30,262 \\
\hline \multirow{9}{*}{200,000} & \multirow{9}{*}{1500} & 10 & 59.83 & 118.43 & 43.77 & 154 & 28,157 \\
\hline & & 20 & 53.06 & 113.61 & 43.2 & 161.7 & 54,036 \\
\hline & & 30 & 53.27 & 107.74 & 42.16 & 169.4 & 78,265 \\
\hline & & 40 & 50.65 & 96.25 & 40.35 & 184.8 & 99,332 \\
\hline & & 50 & 48.47 & 91.95 & 39.15 & 192.5 & 119,606 \\
\hline & & 60 & 46.52 & 88.38 & 37.73 & 200.2 & 134,464 \\
\hline & & 70 & 43.37 & 85.77 & 36.18 & 207.9 & 141,093 \\
\hline & & 80 & 39.73 & 77.77 & 33.54 & 223.3 & 138,194 \\
\hline & & 90 & 39.38 & 76.11 & 31.45 & 231 & 122,574 \\
\hline
\end{tabular}

The results show that the capacities of all equipment tend to decrease with the increase in the desired profit margin. This is because EV charging demand tends to decrease with an increase in the desired profit margin, which results in a decrease in the optimal capacity of equipment. Owing to the charge discount condition in Korea, the CSO business is profitable in all cases except the case of a $10 \%$ profit margin for Case B. The values of weight factors A and B in Table 3 were 1.2 and 0.5, respectively, for the optimal decision in all cases. These values correspond to the condition that the ratio of the capacity of BESS to the contract demand is over 10\%. Specifically, the ratio approximately ranges from $20 \%$ to $70 \%$, even though they are not explicitly shown in the results. Therefore, as a matter of course, a CSO must integrate considerable amount of BESS to become profitable.

The ratio of the optimal capacity of the BESS to that of PCS is around 2 in all the cases. In other words, the BESS may allow two-hour successive charging/discharging operations, but a successive charging/discharging operation lasting more than three hours is prohibited. Thus, it can be concluded that the two-hour successive operation is sufficient for the optimal operation of BESS by a CSO.

To examine the effect of budget and area, the average of the ratio of the optimal solutions, that is, optimal capacities and NPV, between the large and small charging stations are calculated. The results are 4.034, 4.038, and 3.963 for Case A, Case B, and Case C, respectively. The ratio of budget for the large and small charging stations is 4 . Therefore, since the problem at hand is to maximize the profit of the CSO business, budget becomes the dominant factor for the optimal decision, in contrast to the relatively less important condition of area.

Based on the formulation in Section 3, the results in Tables 7-9 are optimal. However, the NPVs for the arbitrarily selected capacities are calculated and compared with the optimal solution for Case A to verify the optimality. Table 10 lists the results. For example, the NPV may decrease by approximately $65 \%$ from 33,404 to 11,627 because of the wrong decision on the capacities of equipment. The values for Case $B$ and Case $C$ provide similar results, even though they are not explicitly shown for conciseness and clarity. Thus, the results in Table 10 show not only the optimality but also the practical usefulness of the proposed method for promoting the expansion of EV charging stations. 
Table 10. Comparison between the NPVs for the arbitrarily selected capacities of equipment in Case A.

\begin{tabular}{|c|c|c|c|c|c|c|c|}
\hline $\begin{array}{c}\text { Budget } \\
\text { (1000 KRW) }\end{array}$ & Area $\left(\mathbf{m}^{2}\right)$ & $\begin{array}{c}\text { Desired Profit } \\
\text { Margin Added to } \\
\text { the Price (\%) }\end{array}$ & $\begin{array}{c}\text { PCS } \\
\text { Capacity } \\
(\mathrm{kW})\end{array}$ & $\begin{array}{c}\text { BESS } \\
\text { Capacity } \\
(\mathrm{kWh})\end{array}$ & $\begin{array}{c}\text { PV } \\
\text { Capacity } \\
(\mathbf{k W})\end{array}$ & $\begin{array}{l}\text { EV Charger } \\
\text { Capacity } \\
\text { (kW) }\end{array}$ & $\begin{array}{l}\text { NPV (1000 } \\
\text { KRW) }\end{array}$ \\
\hline \multirow{5}{*}{50,000} & \multirow{5}{*}{200} & \multirow{5}{*}{50} & 18 & 40 & 10 & 30.8 & 24,142 \\
\hline & & & 11 & 15 & 7 & 61.6 & 11,627 \\
\hline & & & 12 & 17 & 12 & 46.2 & 28,464 \\
\hline & & & 11 & 22 & 13 & 38.5 & 32,514 \\
\hline & & & 11.44 & 21.79 & 13.4 & 38.5 & 33,404 \\
\hline \multirow{5}{*}{200,000} & \multirow{5}{*}{1500} & \multirow{5}{*}{70} & 70 & 150 & 40 & 130.9 & 110,981 \\
\hline & & & 24 & 45 & 23 & 284.9 & 66,217 \\
\hline & & & 60 & 83 & 45 & 146.3 & 132,437 \\
\hline & & & 44 & 84 & 49 & 169.4 & 147,482 \\
\hline & & & 43 & 82.03 & 50.12 & 169.4 & 148,923 \\
\hline
\end{tabular}

As mentioned before, the unit price of equipment is an important factor for determining the equipment's capacity. Thus, to examine the effect of the variation in the unit price of equipment, a sensitivity analysis is performed with the unit price of equipment for Case A. Budget, area, and the desired profit margin are set as 50,000,000 KRW, $200 \mathrm{~m}^{2}$, and 50\%, respectively. The results are shown in Table 11. For each scenario, the unit price of equipment is given as the base price referring to the unit price given in Table 6, except for one that is set as the optimistic or pessimistic price that refers to $75 \%$ or $125 \%$ of the base price, respectively.

Table 11. Sensitivity analysis for the unit price of equipment in Case A.

\begin{tabular}{|c|c|c|c|c|c|c|c|c|}
\hline \multicolumn{4}{|c|}{ Unit Price of Equipment } & \multicolumn{4}{|c|}{ Capacity of Equipment } & \multirow{2}{*}{$\begin{array}{l}\text { NPV } \\
(1000 \\
\text { KRW) }\end{array}$} \\
\hline $\begin{array}{l}\text { PCS (1000 } \\
\text { KRW/kW) }\end{array}$ & $\begin{array}{l}\text { BESS (1000 } \\
\text { KRW/kW) }\end{array}$ & $\begin{array}{c}\text { PV (1000 } \\
\text { KRW/kWh) }\end{array}$ & $\begin{array}{c}\text { EV Charger } \\
(1000 \text { KRW/kW) }\end{array}$ & $\begin{array}{l}\text { PCS } \\
(\mathrm{kW})\end{array}$ & $\begin{array}{l}\text { BESS } \\
\text { (kWh) }\end{array}$ & PV (kW) & $\begin{array}{l}\text { EV Charger } \\
(\mathrm{kW})\end{array}$ & \\
\hline $\begin{array}{c}160 \\
\text { (base) }\end{array}$ & $\begin{array}{c}400 \\
\text { (base) }\end{array}$ & $\begin{array}{l}1500 \\
\text { (base) }\end{array}$ & $\begin{array}{c}450 \\
\text { (base) }\end{array}$ & 11.44 & 21.79 & 13.4 & 38.5 & 33,404 \\
\hline $\begin{array}{l}200 \\
\text { (pes) }\end{array}$ & $\begin{array}{c}400 \\
\text { (base) }\end{array}$ & $\begin{array}{l}1500 \\
\text { (base) }\end{array}$ & $\begin{array}{c}450 \\
\text { (base) }\end{array}$ & 11.16 & 21.24 & 13.28 & 38.5 & 32,566 \\
\hline $\begin{array}{l}120 \\
\text { (opt) }\end{array}$ & $\begin{array}{c}400 \\
\text { (base) }\end{array}$ & $\begin{array}{l}1500 \\
\text { (base) }\end{array}$ & $\begin{array}{c}450 \\
\text { (base) }\end{array}$ & 13.08 & 22.15 & 13.48 & 38.5 & 34,321 \\
\hline $\begin{array}{l}160 \\
\text { (base) }\end{array}$ & $\begin{array}{l}500 \\
\text { (pes) }\end{array}$ & $\begin{array}{l}1500 \\
\text { (base) }\end{array}$ & $\begin{array}{c}450 \\
\text { (base) }\end{array}$ & 11.15 & 19.22 & 12.83 & 38.5 & 29,915 \\
\hline $\begin{array}{l}160 \\
\text { (base) }\end{array}$ & $\begin{array}{l}300 \\
\text { (opt) }\end{array}$ & $\begin{array}{l}1500 \\
\text { (base) }\end{array}$ & $\begin{array}{c}450 \\
\text { (base) }\end{array}$ & 12.06 & 25.1 & 14.12 & 38.5 & 37,766 \\
\hline $\begin{array}{c}160 \\
\text { (base) }\end{array}$ & $\begin{array}{c}400 \\
\text { (base) }\end{array}$ & $\begin{array}{l}1875 \\
\text { (pes) }\end{array}$ & $\begin{array}{l}450 \\
\text { (base) }\end{array}$ & 11.34 & 24.37 & 12.24 & 30.8 & 25,424 \\
\hline $\begin{array}{c}160 \\
\text { (base) }\end{array}$ & $\begin{array}{c}400 \\
\text { (base) }\end{array}$ & $\begin{array}{l}1125 \\
\text { (opt) }\end{array}$ & $\begin{array}{c}450 \\
\text { (base) }\end{array}$ & 13.16 & 29.14 & 15.01 & 38.5 & 42,626 \\
\hline $\begin{array}{c}160 \\
\text { (base) }\end{array}$ & $\begin{array}{c}400 \\
\text { (base) }\end{array}$ & $\begin{array}{l}1500 \\
\text { (base) }\end{array}$ & $\begin{array}{l}563 \\
\text { (pes) }\end{array}$ & 11.16 & 25.95 & 12.59 & 30.8 & 27,031 \\
\hline $\begin{array}{c}160 \\
\text { (base) }\end{array}$ & $\begin{array}{c}400 \\
\text { (base) }\end{array}$ & $\begin{array}{l}1500 \\
\text { (base) }\end{array}$ & $\begin{array}{l}338 \\
\text { (opt) }\end{array}$ & 12.32 & 20.05 & 14.65 & 46.2 & 41,050 \\
\hline
\end{tabular}

In the scenario of an optimistic variation in the unit price of the PCS, the capacity of the PCS increase by $14 \%$ and that of other equipment increases by around $2 \%$ compared with the base price scenario. Similarly, in the scenario of an optimistic variation in the unit price of the BESS, the capacity of the BESS increases by $15 \%$ and that of other equipment increases by around $5 \%$ compared with the base price scenario. On the contrary, in the scenario of an optimistic variation in the unit price of the PV system, the capacity of the PV system increases by only $12 \%$ and that of the PCS and BESS increase by $15 \%$ and $33 \%$, respectively. Moreover, the capacities of the PCS, BESS, and PV system decrease in the scenarios of pessimistic variations in the unit prices of the PCS and BESS; however, the capacity of the PCS barely decreases by less than $1 \%$, that of the BESS increases by $11 \%$, and that of the PV system decreases by $9 \%$ in the scenario of a pessimistic variation in the unit price of the PV system. Additionally, in the scenario of a pessimistic variation in the unit price of the EV chargers, the capacity 
of the BESS increases by $19 \%$ and that of all other equipment decreases. In summary, results of the sensitivity analysis show that increasing the capacity of the ESS is the most efficient way in which to use the proportion of budget secured by variation in the unit price of particular equipment.

\subsection{Discussion}

The simulation results for each case show that the CSO business is economically feasible in most situations. They indicate that a CSO utilizes the advantage of being located in a general commercial area because of the higher NPV for Case A than for Cases B and C. All simulation results are proved optimal by the comparison between the NPVs for the arbitrarily selected capacities of equipment, as shown in Table 10. Thus, the CSO can apply the proposed method or borrow the simulation results in this study to determine the optimal equipment capacity and desired profit margin for a given condition. Specifically, the desired profit margin that leads to the highest NPV is around 70-80\%. Consequently, the so-called "small-profit and quick-return" strategy is unsuitable for a CSO, particularly in this simulation setup.

As mentioned above, the results of the sensitivity analysis for a unit price of equipment indicate that it is the most efficient to use the proportion of the budget that becomes available because of the variation in the unit price of particular equipment for increasing the capacity of the ESS. In other words, ESS is a crucial factor affecting the profit of the CSO because of the charge discount regulations for the ESS installation and operation. Therefore, it is necessary for individuals and companies to carefully monitor the trend in the ESS charge discount policy to make rational investment decisions.

\subsection{Model Statistics}

Table 12 lists the model statistics with details about the size of the model. The number of equations and variables are the same in each simulation. The execution time approximately ranges from 3 to $40 \mathrm{~min}$, and the average execution time for all simulations is about $22 \mathrm{~min}$.

Table 12. Model statistics of the simulations.

\begin{tabular}{cc}
\hline Model Statistics & Value \\
\hline Number of equations & 78,885 \\
Number of variables & 43,834 \\
Non-zero elements & 210,869 \\
Discrete variables & 8761 \\
Average execution time & $1334.664(\mathrm{~s})$ \\
\hline
\end{tabular}

\section{Conclusions}

EVs are one of the most effective means of minimizing negative environmental externalities by reducing greenhouse gases. However, many things need to be accomplished to expand EV integration, particularly in Korea. One important measure is the expansion of EV charging stations. Nevertheless, previous studies did not deal with this issue from the perspective of a CSO, or did not sufficiently address the subject of the optimal investment decision of an individual CSO. However, guaranteed profitability of individual CSOs is considered an essential factor for the deployment of EV charging infrastructure. Therefore, in this study, a novel method to determine the capacities of auxiliary equipment is proposed with the objective of maximizing the profit of an individual CSO.

The optimality of the proposed method is verified using simulations based on the conditions in Korea. Different conditions regarding the EV charging pattern, budget, area, and desired profit margin are considered in these simulations to examine the applicability of the proposed method in various situations. The results show that CSO business is economically feasible in most conditions and that being located in an urban area is advantageous for a CSO. Moreover, it is shown that the "small-profit and quick-return" strategy is not appropriate for a CSO. Further, ESS-related regulations on charge 
discounts significantly affect the optimal investment decision of a CSO. Therefore, individuals and companies with an interest in CSO business must closely watch the trend of the charge discount policy. Consequently, applying the proposed method or borrowing the simulation results in this study can help suggest a CSO's optimal investment solution under certain conditions, thereby contributing to the expansion of the EV charging infrastructure by providing an inducement to invest in the CSO business.

One limitation of this study is that a CSO is assumed to have a single-storied structure with a rooftop PV system since the structural design of a CSO is not the focus of the proposed method. In future research, a method considering various structural designs of CSOs may be developed to address this limitation. Another research strand worth pursuing is the forecast of the deployment level of the EV charging infrastructure using the method of profit maximization of individual CSOs, as compared with methods from the perspective of minimizing total social cost. Thus, future research may prove the validity of the approach to the deployment of EV charging infrastructure from the perspective of individual CSOs.

Author Contributions: S.H.B. designed the study, developed the optimization model, set up the simulation environment, and performed the simulations. Y.G.J. performed the analysis, thoroughly revised the paper, and checked the overall logic of the work. Y.T.Y. provided insightful comments on the modeling and analysis.

Funding: This research was supported by Korea Electric Power Corporation. (Grant number: R18XA03).

Conflicts of Interest: The authors declare no conflict of interest.

\section{Nomenclature}

\begin{tabular}{|c|c|}
\hline \multicolumn{2}{|c|}{ Acronyms } \\
\hline EV & Electric vehicle \\
\hline PCS & Power conditioning system \\
\hline BESS & Battery energy storage system \\
\hline PV & Photovoltaic \\
\hline $\mathrm{CSO}$ & Charging station operator \\
\hline ESS & Energy storage system \\
\hline NPV & Net present value \\
\hline SOC & State of charge \\
\hline \multicolumn{2}{|l|}{ Indices } \\
\hline$h$ & Index of hour \\
\hline$d$ & Index of day \\
\hline \multicolumn{2}{|c|}{ Parameters } \\
\hline$u_{p c S}$ & Unit price of the PCS (KRW/kW) \\
\hline$u_{b}$ & Unit price of the BESS (KRW / kWh) \\
\hline$u_{p v}$ & Unit price of the PV system $(\mathrm{KRW} / \mathrm{kW})$ \\
\hline$u_{e v}$ & Unit price of the EV charger $(\mathrm{KRW} / \mathrm{kW})$ \\
\hline$u_{i}$ & Infrastructure linkage fee (KRW/kW) \\
\hline$u_{c}$ & Unit price of the monthly capacity charge for a CSO to buy electricity from the utility (KRW/kW) \\
\hline$R_{c}$ & Ratio of capacity of grid connection equipment to that of the EV chargers (\%) \\
\hline$A_{\max }$ & Maximum available area of EV charging station $\left(\mathrm{m}^{2}\right)$ \\
\hline$A_{e v}$ & Required area for a single EV charger $\left(\mathrm{m}^{2}\right)$ \\
\hline$A_{p v}$ & Required area for a $1 \mathrm{~kW}$ PV generation system $\left(\mathrm{m}^{2}\right)$ \\
\hline$R_{a}$ & Ratio of area allowed for the EV chargers to area of EV charging station (\%) \\
\hline$C_{s e v}$ & Capacity of a single EV charger $(\mathrm{kW})$ \\
\hline $\mathrm{EX}_{0}^{\max }$ & Allowed budget for the initial capital investment (KRW) \\
\hline$N$ & Number of years in the CSO business \\
\hline$r_{\text {disc }}$ & Annual discount rate $(\%)$ \\
\hline$\eta_{c h}$ & Charging efficiency of the PCS (\%) \\
\hline$\eta_{d c h}$ & Discharging efficiency of the PCS (\%) \\
\hline$S O C_{0}$ & Initial SOC of the BESS (\%) \\
\hline$S O C_{\min }$ & Minimum SOC of the BESS (\%) \\
\hline$S O C_{\max }$ & Maximum SOC of the BESS (\%) \\
\hline
\end{tabular}




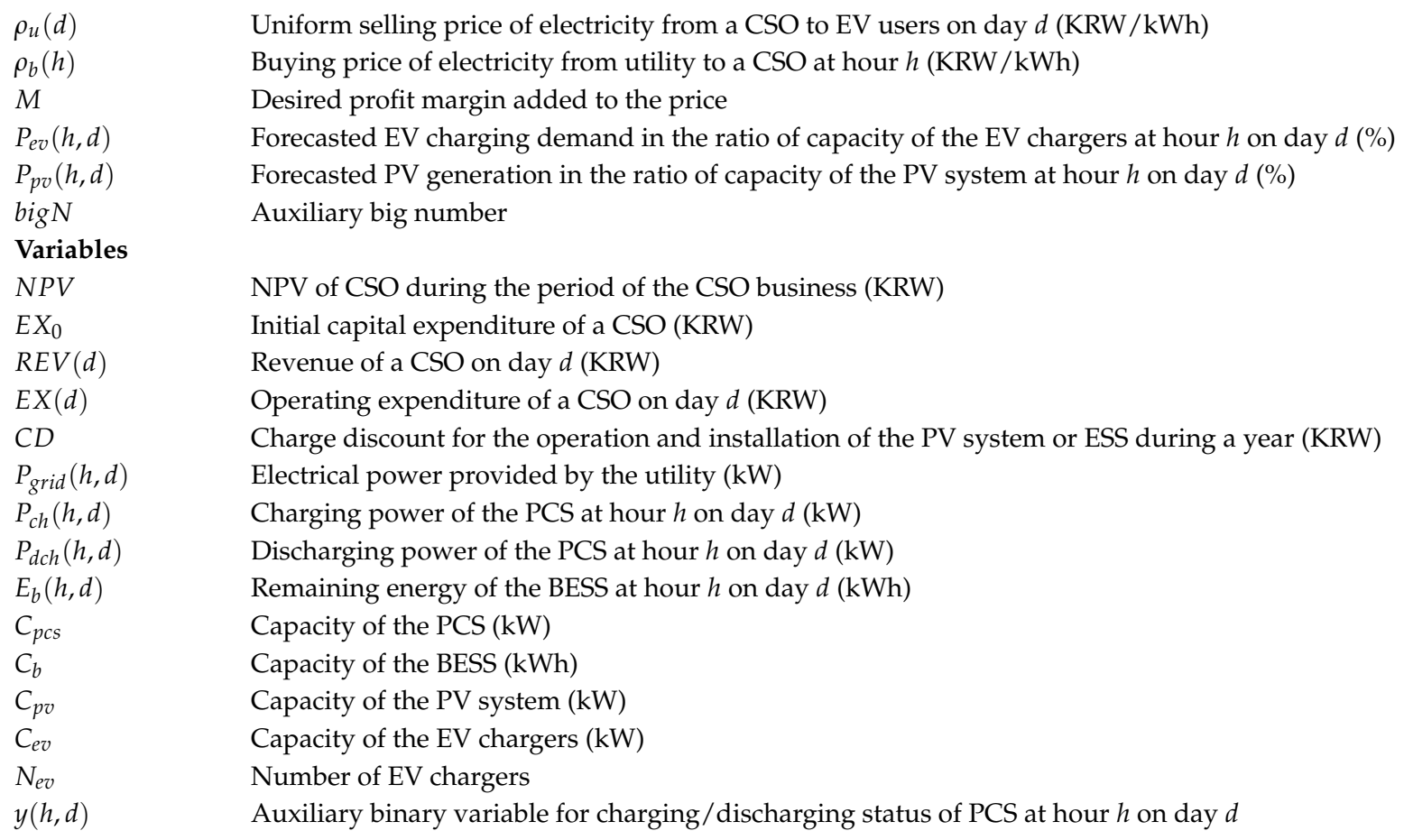

\section{References}

1. Bandivadekar, A.; Bodek, K.; Cheah, L.; Evans, C.; Groode, T.; Heywood, J.; Kasseris, E.; Kromer, M.; Weiss, M. On the Road in 2035: Reducing Transportation's Petroleum Consumption and GHG Emissions; Massachusetts Institute of Technology: Cambridge, MA, USA, July 2008.

2. Shiau, C.-S.N.; Kaushal, N.; Hendrickson, C.T.; Peterson, S.B.; Whitacre, J.F.; Michalek, J.J. Optimal plug-in hybrid electric vehicle design and allocation for minimum life cycle cost, petroleum consumption, and greenhouse gas emissions. J. Mech. Des. 2010, 132, 091013. [CrossRef]

3. EPRI. Environmental Assessment of Plug-in Hybrid Electric Vehicles. Volume 1: Nationwide Greenhouse Gas Emissions; Electric Power Research Institute: Palo Alto, CA, USA, July 2007.

4. IEA. Global EV Outlook 2016; International Energy Agency: Pairs, France, 2016.

5. Ministry of Environment, Republic of Korea. EV Purchase Subsidy Provision. Available online: https: / / ev.or.kr/portal/buyersGuide/incenTive?pMENUMST_ID=21549 (accessed on 29 July 2018).

6. Ministry of Environment, Republic of Korea. EV Supply and Charging Infrastructure Construction Status. 2017. Available online: http://www.me.go.kr//home/web/public_info/read.do;jsessionid= EAg1BATPzfXt48Hdey7ttoTnITniAaGD0DUUBchv1eFcPg4T9WOeSoCqHloCRG9I.meweb1vhost_ servlet_engine1?\&publicInfoId=41\&menuId=10357 (accessed on 29 July 2018).

7. Dong, J.; Liu, C.; Lin, Z. Charging infrastructure planning for promoting battery electric vehicles: An activity-based approach using multiday travel data. Transp. Res. Part C Emerg. Technol. 2014, 38, 44-55. [CrossRef]

8. Kontou, E.; Yin, Y.; Lin, Z.; He, F. Socially optimal replacement of conventional with electric vehicles for the US household fleet. Int. J. Sustain. Transp. 2017, 11, 749-763. [CrossRef]

9. Luo, L.; Gu, W.; Zhou, S.; Huang, H.; Gao, S.; Han, J.; Wu, Z.; Dou, X. Optimal planning of electric vehicle charging stations comprising multi-types of charging facilities. Appl. Energy 2018, 226, 1087-1099. [CrossRef]

10. Román, T.G.S.; Momber, I.; Abbad, M.R.; Miralles, Á.S. Regulatory framework and business models for charging plug-in electric vehicles: Infrastructure, agents, and commercial relationships. Energy Policy 2011, 39, 6360-6375. [CrossRef]

11. Madina, C.; Zamora, I.; Zabala, E. Methodology for assessing electric vehicle charging infrastructure business models. Energy Policy 2016, 89, 284-293. [CrossRef]

12. Sweda, T.; Klabjan, D. An agent-based decision support system for electric vehicle charging infrastructure deployment. In Proceedings of the 7th IEEE Vehicle Power and Propulsion Conference, Chicago, IL, USA, 6-9 September 2011. 
13. Liu, J. Electric vehicle charging infrastructure assignment and power grid impacts assessment in Beijing. Energy Policy 2012, 51, 544-557. [CrossRef]

14. Trivedi, A.; Menon, B.; Srinivasan, D.; Sharma, A.; Nicholas, W.F.D. Multi-Objective Siting and Sizing of E Charging Stations in the Distribution System. In Proceedings of the IEEE Smart Grid Technologies-Asia (ISGT ASIA), Bangkok, Thailand, 3-6 November 2015; pp. 1-6.

15. Liu, Z.; Wen, F.; Ledwich, G. Optimal planning of electric-vehicle charging stations in distribution systems. IEEE Trans. Power Deliv. 2013, 28, 102-110. [CrossRef]

16. Sadeghi-Barzani, P.; Rajabi-Ghahnavieh, A.; Kazemi-Karegar, H. Optimal fast charging station placing and sizing. Appl. Energy 2014, 125, 289-299. [CrossRef]

17. Jia, L.; Hu, Z.; Song, Y.; Luo, Z. Optimal siting and sizing of electric vehicle charging stations. In Proceedings of the IEEE International Electric Vehicle Conference, Greenville, SC, USA, 4-8 March 2012; pp. 1-6.

18. Liu, Z.; Wen, F.; Ledwich, G. Optimal siting and sizing of distributed generators in distribution systems considering uncertainties. IEEE Trans. Power Deliv. 2011, 26, 2541-2551. [CrossRef]

19. Chandra Mouli, G.R.; Bauer, P.; Zeman, M. System design for a solar powered electric vehicle charging station for workplaces. Appl. Energy 2016, 168, 434-443. [CrossRef]

20. Bai, S.; Yu, D.; Lukic, S. Optimum design of an EV/PHEV charging station with DC bus and storage system. In Proceedings of the Energy Conversion Congress and Exposition (ECCE), Atlanta, GA, USA, 12-16 September 2010.

21. The Manual of Korea Power Market Operation. Available online: http://www.kpx.or.kr/www/ selectBbsNttList.do?bbsNo=114\&key=29 (accessed on 29 July 2018).

22. Enforcement Decree of Electricity Business Act. Available online: http://www.law.go.kr/lsInfoP.do?lsiSeq= 200249\&efYd=20171226\#0000 (accessed on 29 July 2018).

23. KEPCO. Detailed Regulations for Billing Provisions for Electricity Supply. Available online: https: / / cyber. kepco.co.kr/ckepco/front/jsp/CY / D/C/CYDCHP00201.jsp (accessed on 29 July 2018).

24. KEPCO. Notification of Changed Fee Discount Regulation for Renewable Energy Resources and Energy Storage System. Available online: http:/ /home.kepco.co.kr/kepco/CU/A/B/CUABPP00102.do? pageIndex=1\&boardSeq=21029313\&menuCd=FN1201 (accessed on 29 July 2018).

25. KEPCO. Billing Provisions for Electricity Supply. Available online: http://cyber.kepco.co.kr/ckepco/front/ jsp/CY/D/C/CYDCHP00101.jsp (accessed on 29 July 2018).

26. Khalilpour, R.; Vassallo, A. Planning and operation scheduling of PV-battery systems: A novel methodology. Renew. Sustain. Energy Rev. 2016, 53, 194-208. [CrossRef]

27. Ministry of Environment, Republic of Korea. Instruction for Installation and Operation of EV Charging Infrastructure. 2018. Available online: https:/ / ev.or.kr/portal/board/14/2447/?pMENUMST_ID=21552 (accessed on 29 July 2018).

28. PRPA. Battery Energy Storage Technology Assessment; Platte River Power Authority: Fort Collins, CO, USA, 2017.

29. Fu, R.; Feldman, D.J.; Margolis, R.M.; Woodhouse, M.A.; Ardani, K.B. U.S. Solar Photovoltaic System Cost Benchmark: Q1 2017; National Renewable Energy Laboratory: Golden, CO, USA, September 2017.

30. U.S. Energy Information Administration. Today in Energy. Available online: https://www.eia.gov/ todayinenergy / detail.php?id=35432 (accessed on 29 July 2018).

31. OhmHome. EV Charging Station Cost. Available online: https://www.ohmhomenow.com/electricvehicles/ev-charging-station-cost/ (accessed on 29 July 2018).

32. Fesharaki, V.J.; Dehghani, M.; Fesharaki, J.J.; Tavasoli, H. The effect of temperature on photovoltaic cell efficiency. In Proceedings of the 1st international conference on emerging trends in energy conservation-ETEC, Tehran, Iran, 21-22 November 2011.

33. NOAA. Quality Controlled Datasets. Available online: https://www.ncdc.noaa.gov/crn/qcdatasets.html (accessed on 29 July 2018).

(C) 2018 by the authors. Licensee MDPI, Basel, Switzerland. This article is an open access article distributed under the terms and conditions of the Creative Commons Attribution (CC BY) license (http:/ / creativecommons.org/licenses/by/4.0/). 